\title{
Social Laughter Triggers Endogenous Opioid Release in Humans
}

\author{
Sandra Manninen, ${ }^{1}$ Lauri Tuominen, ${ }^{1}$ Robin I. Dunbar, ${ }^{2,3}$ Tomi Karjalainen, ${ }^{1}$ Jussi Hirvonen, ${ }^{1}$ Eveliina Arponen, ${ }^{1}$ \\ Riitta Hari, ${ }^{2,4}$ Iiro P. Jääskeläinen, ${ }^{2}$ Mikko Sams, ${ }^{2}$ and ${ }^{\circ}$ Lauri Nummenmaa ${ }^{1,5}$ \\ ${ }^{1}$ Turku PET Centre, University of Turku, 20520 Turku, Finland, ${ }^{2}$ Department of Neuroscience and Biomedical Engineering, School of Science, Aalto \\ University, 00076 Aalto, Finland, ${ }^{3}$ Department of Experimental Psychology, University of Oxford, OX1 3UD Oxford, United Kingdom, ${ }^{4}$ Department of Art, \\ School of Arts, Design and Architecture, Aalto University, 00076 Aalto, Finland, and 5 Department of Psychology, University of Turku, 20014 Turku, Finland
}

The size of human social networks significantly exceeds the network that can be maintained by social grooming or touching in other primates. It has been proposed that endogenous opioid release after social laughter would provide a neurochemical pathway supporting long-term relationships in humans (Dunbar, 2012), yet this hypothesis currently lacks direct neurophysiological support. We used PET and the $\mu$-opioid-receptor (MOR)-specific ligand $\left[{ }^{11} \mathrm{C}\right]$ carfentanil to quantify laughter-induced endogenous opioid release in 12 healthy males. Before the social laughter scan, the subjects watched laughter-inducing comedy clips with their close friends for $30 \mathrm{~min}$. Before the baseline scan, subjects spent $30 \mathrm{~min}$ alone in the testing room. Social laughter increased pleasurable sensations and triggered endogenous opioid release in thalamus, caudate nucleus, and anterior insula. In addition, baseline MOR availability in the cingulate and orbitofrontal cortices was associated with the rate of social laughter. In a behavioral control experiment, pain threshold-a proxy of endogenous opioidergic activation - was elevated significantly more in both male and female volunteers after watching laughter-inducing comedy versus non-laughter-inducing drama in groups. Modulation of the opioidergic activity by social laughter may be an important neurochemical pathway that supports the formation, reinforcement, and maintenance of human social bonds.

Key words: bonding; carfentanil; emotion; laughter; opioids; positron emission tomography

\section{Significance Statement}

Social contacts are vital to humans. The size of human social networks significantly exceeds the network that can be maintained by social grooming in other primates. Here, we used PET to show that endogenous opioid release after social laughter may provide a neurochemical mechanism supporting long-term relationships in humans. Participants were scanned twice: after a 30 min social laughter session and after spending $30 \mathrm{~min}$ alone in the testing room (baseline). Endogenous opioid release was stronger after laughter versus the baseline scan. Opioid receptor density in the frontal cortex predicted social laughter rates. Modulation of the opioidergic activity by social laughter may be an important neurochemical mechanism reinforcing and maintaining social bonds between humans.

\section{Introduction}

Humans and other primates use social touching or grooming for reinforcing social structures (Dunbar and Shultz, 2010; Suvilehto

Received March 2, 2016; revised March 13, 2017; accepted April 10, 2017.

Author contributions: L.T., R.I.D., J.H., R.H., I.P.J., M.S., and L.N. designed research; S.M., L.T., R.I.D., and E.A. performed research; S.M., L.T., T.K., and L.N., analyzed data; S.M., L.T., R.I.D., T.K., J.H., R.H., I.P.J., M.S., and L.N. wrote the paper.

This work was supported by the Academy of Finland (Grants 265915 and 294897 to L.N., Grant 276643 to I.P.J., and Grant 218072 to R.H.), the European Research Council (Starting Grant 313000 to L.N. and Advanced Grants 232946 to R.H. and 295663 to R.D.). The funders had no role in study design, data collection and analysis, decision to publish, or preparation of the manuscript.

The authors declare no competing financial interests.

Correspondence should be addressed to Lauri Nummenmaa, Turku PET Centre, Kiinamyllynkatu 4-6, FI-20520 Turku, Finland. E-mail: latanu@utu.fi. et al., 2015). Because blockade of opioid receptors stimulates grooming and social behavior in primates (Meller et al., 1980; Fabre-Nys et al., 1982), it has been proposed that touchingdependent modulation of the $\mu$-opioid-receptor (MOR) system might support maintenance of social bonds. However, because the size of human social networks exceeds the network that can be maintained by dyadic social touching (Dunbar, 2012), it has been proposed that other means such as social laughter have evolved to release endogenous opioids just as grooming does. Because social laughter could allow simultaneous opioid release among all the members of an interacting group, it might play a critical role in 
enabling humans to live in exceptionally large social networks (Dunbar, 2012). However, the neurochemical basis of human social laughter remains poorly understood.

The MORs mediate the effects of endogenous and exogenous opioids contributing to the rewarding effects of food and drugs (Henriksen and Willoch, 2008; Nummenmaa and Tuominen, in press). Endogenous opioids modulate prosocial behavior in polygamous rodents (Panksepp et al., 1980) and MOR gene-knockout mice pups display deficits in attachment behavior (Moles et al., 2004). Rhesus infants carrying a gain-of-function OPRM1 $77 \mathrm{G}$ allele experience increased reward from maternal contact and display increased measures of attachment (Barr et al., 2008), whereas, in humans, A118G polymorphism of the OPRM1 is associated with enhanced dispositional and neural sensitivity to social rejection (Way et al., 2009). Consistent with these findings, elevated cerebral MOR availability is associated with secure social attachment behavior in humans (Nummenmaa et al., 2015). Finally, opioid receptor antagonists increase the frequency of grooming (Fabre-Nys et al., 1982) and grooming solicitations (Keverne et al., 1989) in primates, adding to the evidence that the opioid system may underlie social bonding.

Grooming-based social bonding imposes severe constraints on the maximum possible size of social groups (Dunbar, 1991). Therefore, ecological pressures demanding larger group sizes have led to the evolution of more effective mechanisms for facilitating social bonding (Dunbar, 2008). Laughter is a universally recognized expression of positive social emotion, occurring most frequently in human social interactions (Sauter et al., 2010; Scott et al., 2014) but is also present in nonhuman primates (Preuschoft, 1992; Davila Ross et al., 2009). Humans volitionally laugh as an expression of prosociality, possibly for bonding purposes (Scott et al., 2014), and shared sense of humor is indeed a strong predictor of affiliation and altruism (Curry and Dunbar, 2013). Because laughter is highly contagious (Provine, 2004), it would allow MOR responses to spread throughout the interacting group to increase the effectiveness of this type of "vocal grooming" (Dunbar, 2012).

Here we tested directly whether social laughter results in cerebral opioid release, as quantified with in vivo PET. Measures of MOR availability were acquired with the MOR-specific ligand $\left[{ }^{11} \mathrm{C}\right] \mathrm{car}-$ fentanil during two separate sessions: social laughter and a neutral baseline condition. Under this experimental design, endogenous opioid release would be manifested as lower $\left[{ }^{11} \mathrm{C}\right]$ carfentanil binding potential (the ratio of specific to nondisplaceable binding in the brain, $B P_{\mathrm{ND}}$ ) in the social laughter versus baseline condition. Building on animal research on grooming-dependent MOR activation, we expected to see significantly increased MOR activation in the social laughter condition.

\section{Materials and Methods}

Subjects and self-reports. The study protocol was approved by the ethics board of the Hospital District of Southwest Finland and the study was conducted in accordance with the Declaration of Helsinki. Twelve healthy male adults (age range $20-32$ years, mean $=22.9, \mathrm{SD}=3.26$ ) volunteered for the study. Only young males were scanned because age and sex influence both MOR availability and the capacity to engage the MOR system (Gabilondo et al., 1995; Zubieta et al., 1999). In addition to standard PET and MRI exclusion criteria, subjects were excluded if they met any of the following criteria: poor compliance, smoking, excessive alcohol consumption ( $>8$ units/week), use of illicit drugs, current medication affecting the CNS, or a history of or current neurological or psychiatric disease confirmed using the structured clinical interview for DSM-IV, medical history, and blood tests. Subjects were compensated for their time and travel costs and they signed ethics-committeeapproved informed consent forms. Subjects reported their mood (sleep- iness, happiness, tension, irritability, pain, pleasure, calmness, and amusement) using a visual analog scale (range $0-100$ ). Responses were recorded at the beginning ( $0 \mathrm{~min}$; immediately after the laughter/baseline manipulation), in the middle (27 $\mathrm{min})$, and at the end $(51 \mathrm{~min})$ of the PET scans (see below).

Social laughter manipulation. Each subject underwent two PET scans on the same day: a social laughter scan and a neutral baseline scan. Before the social laughter scan, the subject and his two close friends watched preselected comedy clips together for $30 \mathrm{~min}$ in a private room. Subjects were seated in front of a data projector screen and given access to a computer with a preselected playlist of short, amusing comedy clips on YouTube. They were then asked to watch the clips similarly as they would be watching TV. A similar protocol has been validated previously to trigger social laughter reliably (Dunbar et al., 2012). Social laughter manipulation was performed before rather than during the PET scan to avoid laughing-related head and other bodily movements during data acquisition. Before the baseline scan, the subjects spent $30 \mathrm{~min}$ alone in the preparation room without contacts with other individuals.

During prescan laughter manipulation, the sounds of social laughter were recorded with an Olympus Digital Recorder VN-711PC. The recorder was placed in the middle of the room and the microphone was aimed at the subjects. Subsequently, frequency of laughter bursts was coded from the recordings. Two laughter bursts were considered as distinct if they were separated by at least $3 \mathrm{~s}$ of silence. Nonspecific sounds, such as humming, coughing, or amused speaking were not considered as laughs. Because this laughter measure did not differentiate between laughter of the scanned subject versus the two accompanying subjects, the subjects also reported, on a laughter-rate-scale ranging from 0 to 100 , how much they thought they laughed throughout the session.

PET data acquisition and analysis. PET scans immediately followed the laughter and baseline conditions. During the PET acquisition, the subject was lying in the PET scanner wearing hospital clothes and covered with blankets. The lights in the scanner room were dimmed. Social laughter and baseline conditions were separated by a $2 \mathrm{~h}$ break to allow for tracer decay. The order of the scans was counterbalanced across subjects.

Data were acquired with Philips Ingenuity PET-MR scanner at Turku PET Centre. Radiotracer production has been described previously (Hirvonen et al., 2009; Karlsson et al., 2015). After intravenous ( $M=250$ $\mathrm{MBq}, \mathrm{SD}=28 \mathrm{MBq}$ ) radioligand (mean injected mass $0.34 \mu \mathrm{g}$ ) bolus injection, radioactivity in the brain was measured with the PET camera for $51 \mathrm{~min}$ with an in-plane resolution of $3.75 \mathrm{~mm}$. The subjects were lying in a supine position throughout the studies. Data were corrected for dead time, decay, and measured photon attenuation and dynamic PET scans were reconstructed using the MRP reconstruction method (Alenius and Ruotsalainen, 1997). High-resolution $\left(1 \mathrm{~mm}^{3}\right)$ anatomical MR reference images were acquired using a T1-weighted sequence (TR $25 \mathrm{~ms}$, TE $4.6 \mathrm{~ms}$, flip angle $30^{\circ}$, scan time $376 \mathrm{~s}$ ).

To correct for head motion, dynamic PET images were first realigned frame to frame. The individual T1-weighted MR images were coregistered to the summation images calculated from the realigned frames. Reference regions were drawn manually on MRI images using PMOD 3.4 software (PMOD Technologies). Receptor availability was expressed in terms of $B P_{\mathrm{ND}}$. We used the occipital cortex as the reference region because it is known to be practically devoid of MOR (Hiller and Fan, 1996). $B P_{\mathrm{ND}}$ was calculated for each voxel using the simplified reference tissue model with reference-tissue time activity curves as input data (Gunn et al., 1997). This outcome measure is not confounded by blood flow or tracer transport (Sander et al., 2014). The subject-wise parametric $B P_{\mathrm{ND}}$ images were normalized to MNI space using the T1-weighted MR images and smoothed with a Gaussian kernel of $8 \mathrm{~mm}$ FWHM.

The effects of social laughter on MOR availability were then assessed in SPM12 (http://www.fil.ion.ucl.ac.uk/spm/) using a repeated-measures $t$ test. Statistical threshold was set at $p<0.05$, FDR corrected at cluster level. Effect size maps (Cohen's $d$ ) were also computed to allow visual inspection of the magnitude of the observed $B P_{\mathrm{ND}}$ changes. Linear regression analysis was further used to test whether baseline MOR availability would be associated with social laughter rate in the laughter manipulation. In a complementary approach, we also computed and visualized these associations in anatomical regions of interest (ROIs) 

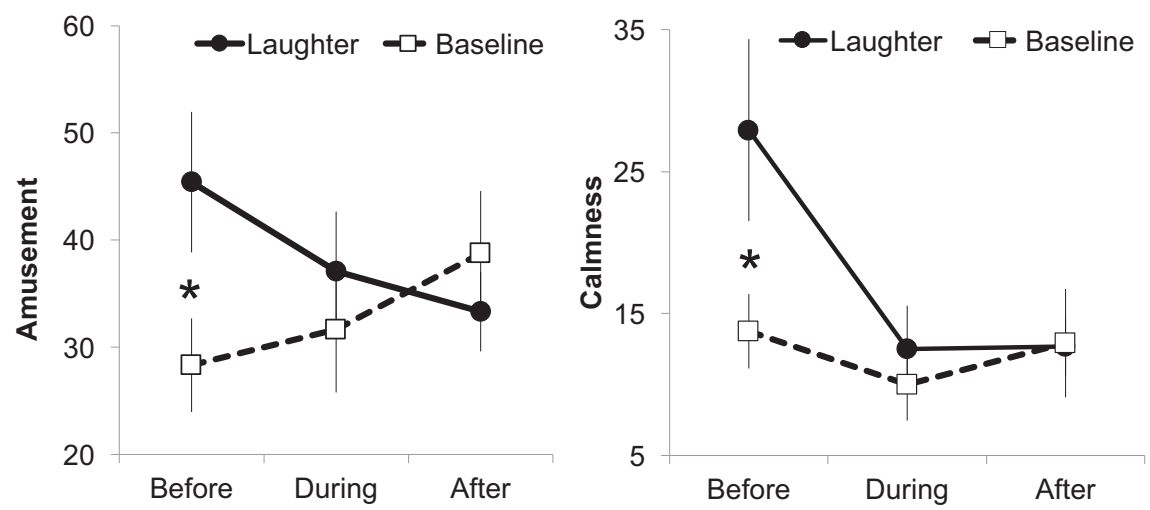

Figure 1. Self-reported amusement and calmness before, during, and after the PET scans in the laughter and baseline conditions. Asterisks denote significant between-conditions differences. Note that the first time point ("before") was recorded immediately after the laughter/baseline manipulation and before entering the PET scanner.

generated in key components of the reward circuit and regions critical for socioemotional processing (thalamus, ventral striatum, dorsal caudate, amygdala, insula, orbitofrontal cortex, and anterior, medial, and posterior cingulate cortices) delineated using the AAL (Tzourio-Mazoyer et al., 2002) and Anatomy toolboxes (Eickhoff et al., 2005). Striatal divisions were performed manually as described previously (Kätsyri et al., 2013).

\section{Results}

Viewing the comedy clips successfully elicited group laughter, with a mean rate of $1.04(\mathrm{SD}=0.60)$ recorded laughter bursts per minute. The objective group laughter rate also correlated significantly with subjects' self-reported laughter rate $(\mathrm{M}=61, \mathrm{SD}=$ $\left.21 r_{s}=0.57, p=0.05\right)$. Self-reports revealed that social laughter led to increased experience of amusement and calmness at the beginning $(p<0.05)$, but not at the midpoint or endpoint of the scans (Fig. 1). Whole-brain analysis of the PET data revealed that social laughter increased endogenous opioid release (as reflected by decreased $\left[{ }^{11} \mathrm{C}\right]$ carfentanil $B P_{\mathrm{ND}}$ ) in several brain regions including thalamus, caudate nucleus and putamen, and the insular, cingulate, and frontal cortices. Opposite effects were observed in middle cingulate cortices (see Fig. 2 for effect size and $t$-contrast maps).

Because MOR tone is known to be positively associated with self-reported sociability, we next tested whether baseline MOR availability would predict the frequency of social laughter bursts in the pre-experimental manipulation. Full-volume analyses (Fig. 3) revealed widespread positive associations, most profoundly observed in orbitofrontal and cingulate cortices and in the ventral striatum. Analysis based on the self-reported laughter scores yielded essentially a similar pattern of results (data not shown). Results from anatomical ROI analyses (Fig. 4) paralleled those of the full-volume analyses, with significant associations $\left(r^{2}\right.$ $>0.38, p<0.05$ ) observed in anterior, middle, and posterior cingulate cortices, orbitofrontal cortex, and ventral striatum.

Because we scanned only males and used a low-level baseline condition (spending $30 \mathrm{~min}$ alone in the control room), the data do not show conclusively that social laughter per se would have triggered the observed endogenous opioid release and that this effect would occur in both sexes. To control for these issues, we reanalyzed our previous data (Dunbar et al., 2012) on the effects of social laughter on pain thresholds (as a proxy for endogenous opioid release). In this study, male and female subjects viewed either live comedy or drama and performed a "wall-sit" exercise as a pain threshold assay $1 \mathrm{~h}$ before and immediately after the comedy/drama shows. In this task, the subjects lean against a wall with legs at right angles until it becomes too painful and they collapse to the ground. The reanalysis revealed that the pain threshold was significantly higher in the (laughterinducing) comedy versus drama condition $\left(t_{(29)}=2.54, p=0.017\right)$, suggesting that laughter and not the mere social presence of others is necessary for the endogenous opioid release. Importantly, there was no difference between pain threshold change between males and females $(p=$ $0.93, \mathrm{M}_{\text {males }}=49.3 \pm 16.0 \mathrm{~s}, \mathrm{M}_{\mathrm{females}}=$ $47.4 \pm 10.3 \mathrm{~s}$ ).

Because laughter and subjective experience of pleasure were not recorded directly in the above study, we also ran a new control experiment ( 19 females, 24 males) in which we measured laughter rates and acquired subjective ratings of amusement from male and female subjects while they viewed 30 min medleys of comedy movies versus neutral movie clips, similar to the main experiment. Laughter rate $\left(F_{(1,39)}=\right.$ 14.83, $\left.p<0.001, \eta_{\mathrm{p}}{ }^{2}=0.28\right)$ and subjective experience of amusement $\left(F_{(1,39)}=7.62, p<0.01, \eta_{\mathrm{p}}{ }^{2}=0.16\right)$ were significantly higher in the comedy versus neutral movie conditions, and there were no differences between male and female subjects $(p>0.47)$.

\section{Discussion}

Our results demonstrate for the first time that social laughter is associated with MOR system activation and that baseline MOR availability specifically predicts the amount of experimentally induced social laughter. Laughter triggered endogenous opioid release in brain regions involved in processing of rewards and arousal (thalamus, caudate nucleus), but also in the insular cortices that have been associated with interoceptive, gustatory, and nociceptive processing (Wicker et al., 2003; Critchley et al., 2004; Singer et al., 2004). Our results show that social laughter triggers endogenous opioid release, which could provide a powerful way for modulating social bonds in groups. Together, these results suggest that the opioid system plays a key role in mammalian prosocial communication and possibly also in social bonding, in addition to the well known oxytocin and vasopressin systems (Young et al., 2001).

Social laughter increased positive mood and calmness, in accordance with the anxiolytic effects of exogenous opioid agonists (Colasanti et al., 2011). Laughter and positive facial expressions are important prosocial signals in humans (Scott et al., 2014) and also in nonhuman primates. Macaques and chimpanzees use a quiet, smile-like gesture to appease aggressive conspecifics, whereas relaxed, open-mouth vocalizations are associated with both play behavior and pair formation (Preuschoft, 1992; Waller and Dunbar, 2005). Prior studies have found that laughter involves engagement of both affective and reward networks in the brain (Wild et al., 2003). Therefore, we propose that laughter-evoked, coordinated MOR activity in these systems could constitute a candidate neurochemical mechanism underlying incentive motivation toward bonding. The present results also agree with the general role of the endogenous opioids in prosociality. For example, the opioid antagonist naltrexone increases self-reported pain ratings and unpleasant experiences when seeing others in pain (Rütgen et al., 2015b). Placebo analgesia mediated by the opioidergic system (Peciña and Zubieta, 2015) re- 

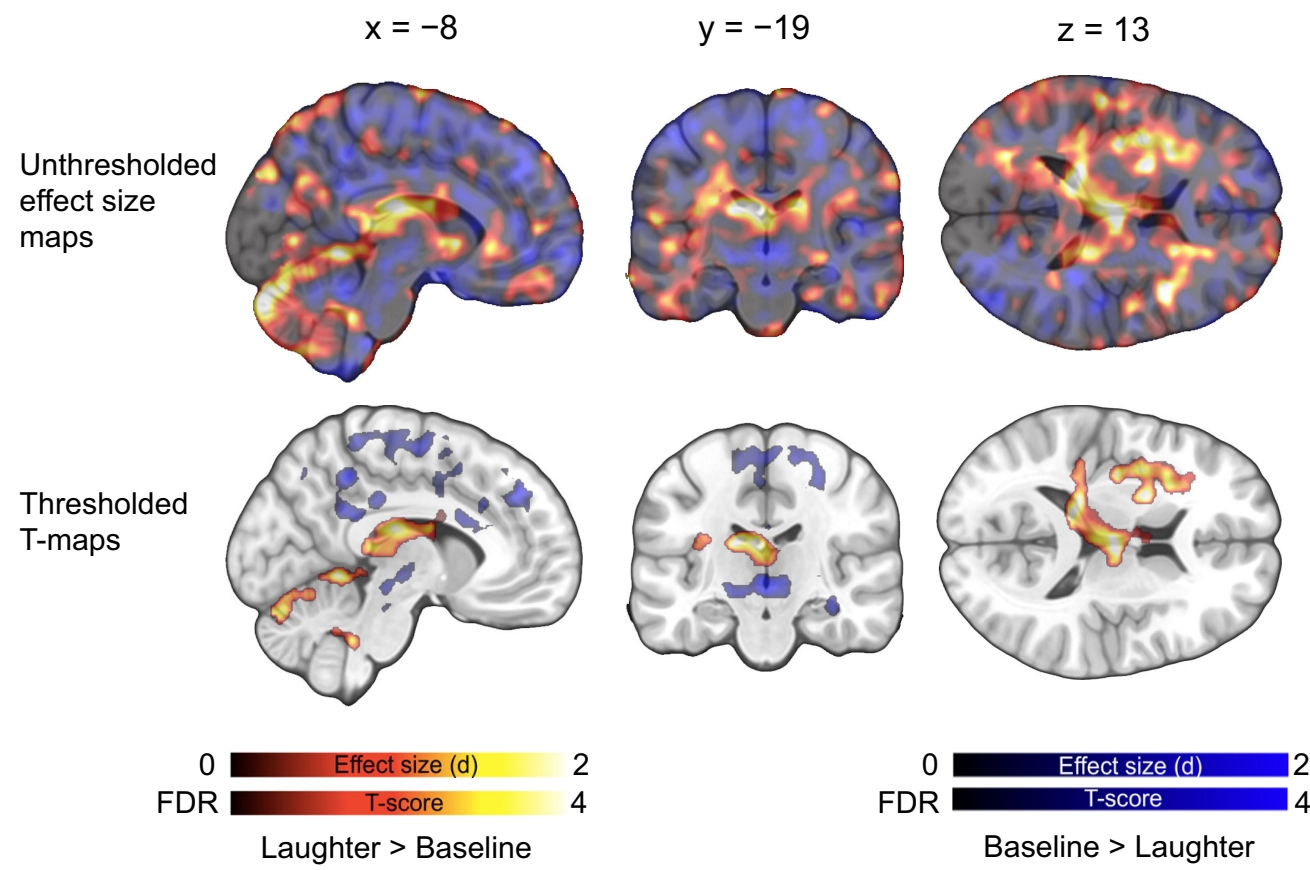

Figure 2. Brain regions showing increased (hot colors) and decreased (cool colors) endogenous opioid release during the social laughter versus baseline conditions. Top row shows unthresholded effect size maps; bottom row T-contrast maps thresholded at $p<0.05$, FDR corrected at the cluster level. Colored bars denote the $d / T$ statistic ranges.

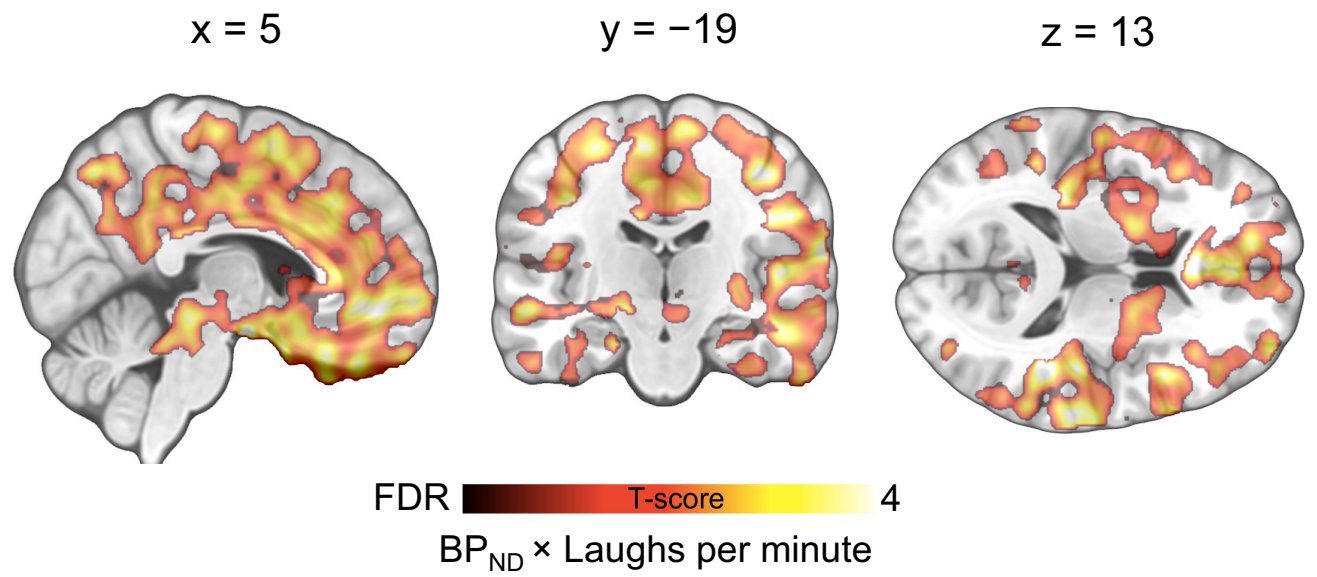

Figure 3. Brain regions showing significant association between baseline MOR availability and frequency of recorded social laughter bursts (laughs per minute). The data are thresholded at $p<$ 0.05 , FDR corrected at the cluster level.

duces negative emotional experiences when seeing others in distress, which is also reflected as attenuated brain responses to seeing others experiencing pain (Rütgen et al., 2015a; Rütgen et al., 2015b).

Our results parallel those stemming from pharmacological manipulation studies on the opioidergic basis of social grooming in nonhuman primates (Fabre-Nys et al., 1982; Graves et al., 2002). It is thus possible that human social laughter could support similar social functions as grooming does in humans and other primates, that is reducing tension (cf. self-report data) and anxiety-related behaviors (Graves et al., 2002), also including establishing and maintaining social structures (Dunbar and Shultz, 2010; Suvilehto et al., 2015). In agreement with these findings, significant laughter-induced MOR activation was also observed in the anterior insula. The unmyeliated C-tactile fibers project to the insula, but not to the primary somatosensory cortices (Olausson et al., 2002), and this tactile system responding to slow, pleasurable stroking may provide the sensory pathway for emotional and affiliative touching. Along with prior functional imaging studies showing insula activation while subjects listen to vocal laughter bursts (Sander and Scheich, 2005), our data support the claim that social laughter may engage the same affectivesensory circuits as does physical grooming, which is consistent with Darwin's original proposal that laughter is a kind of "tickling of the mind" (Darwin, 1872).

Surprisingly, we also observed decreased laughter-triggered opioid activity in the cortical midline regions. Although such observations are not uncommon in studies with $\left[{ }^{11} \mathrm{C}\right]$ carfentanil (Hsu et al., 2013), their interpretation is not straightforward. Decrease in $B P_{\mathrm{ND}}$ may result from externalization or conformational changes in the receptors, but whether it is caused by increased or decreased endogenous opioid tone cannot be determined within the current design.

Unlike grooming, social laughter allows engagement of the MOR-dependent bonding mechanism among all members of an interacting group. Laughter is highly contagious and, in an ap- 

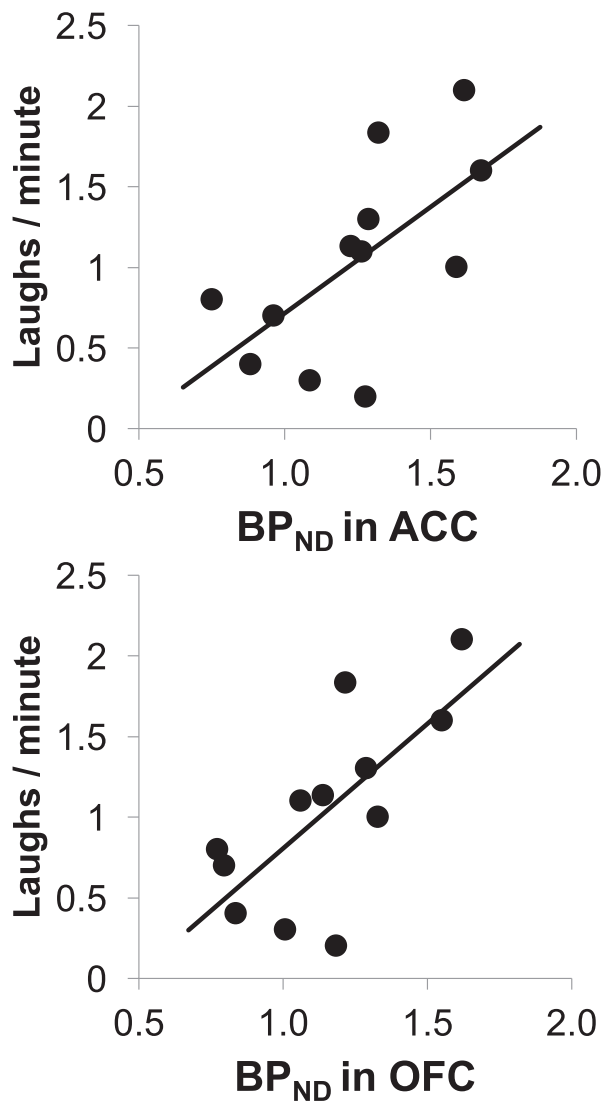

Figure 4. Association between baseline MOR availability and social laughter rate (laughs per minute) in orbitofrontal cortex (OFC), ventral striatum (vSTR), and anterior (ACC) and middle (MCC) cingulate cortices (all $p<0.05$ ). Cook's distances $<0.57$ for all observations suggest that no single data point or removal of such drives the correlations significantly. cortices supporting socioemotional functions. These results provide direct evidence for the hypotheses that MOR availability is associated with sociability and reward-sensitivity, as indicated previously by correlational PET studies (Nummenmaa et al., 2015). Importantly, full-volume analysis also revealed an association between laughter rate and MOR availability in the amygdala. The role of the amygdala in nonverbal emotional processing is well established (Sander and Scheich, 2005) and functional neuroimaging studies have shown that the amygdala is involved in involuntary (emotional) but not voluntary laughter (Wild et al., 2003; Scott et al., 2014). High availability of MORs may enhance the calming effects of endogenously released opioid peptides acting on the MOR during social laughter, thus promoting reinforcement of attachment bonds. Genetically determined individual differences in opioidergic neurotransmission influence social behavior (Moles et al., 2004; Barr et al., 2008; Way et al., 2009). It is therefore likely that genetically determined MOR expression contributes significantly to this effect; nonetheless, neuroplastic changes in the MOR system after repeated exposures to pleasurable social interaction likely play a role too.

Humans have an urgent need to feel like they belong to groups and most studies have shown that both large social networks and the availability of social propriately pleasurable context, simply hearing the sound of laughing may be sufficient to trigger laughter (Provine, 2004). This, in turn, may engage the MOR system of all individuals in the group hearing the laughter. Therefore, laughter imposes less severe timing constraints on social bonding compared with grooming and it could thus play a key role in enabling humans to live in exceptionally large social networks with numerous affiliative and nonreproductive relationships (Dunbar, 2012). Such laughterbased bonding mechanisms are functional very early on during human development; spontaneous laughter and smiles are the very first prosocial gestures that infants direct toward their caregivers. Because the occurrence of infant smiles is strongly related to the caregiver's positive emotions (Mireault et al., 2015), laughter and smiling are thought to reflect coordinated bonding behavior within the infantcaregiver dyad. Due to the spreading of the opioidergic response across listeners, social laughter likely plays a major role in early socialization of the infant to their family and their proximal social networks, as well as directly underpinning the mother-infant bond. However, we stress that our data pertain strictly to laughter-induced opioid release and, even though this parallels the well known effects of opioids on social bonding in other primates, further work is required to establish causal relationships between laughter-induced opioid release and social bonding.

Baseline MOR availability predicts the rate of social laughter Baseline MOR availability predicted linearly the rate of social laughter during the experimental laughter manipulation. This effect was observed in the key nodes of the reward circuit (amygdala and ventral striatum) and in the frontal and cingulate support are associated with beneficial effects for somatic health in humans (Broadhead et al., 1983; Liu and Newschaffer, 2011; Holt-Lunstad et al., 2015) and with infant survival in monkeys (Silk et al., 2003). Prior studies also suggest that such laughterdependent effects on somatic health occur already at the level of the immune system. Social laughter releases immunoenhancers (such as $\beta$-endorphins), but it also increases the activity of natural killer cells (lymphocytes) and lowers cortisol levels in blood circulation (Berk et al., 1989). Because both the tendency to avoid intimate social interactions (Nummenmaa et al., 2015) and the occurrence of mood disorders are associated with lower regional availability of MOR (Kennedy et al., 2006), the present data show that laughter may not only be an important mechanism for maintaining social relationships, but also an effective behavioral coping mechanism against stressful situations.

\section{Limitations}

It must be noted that the observed $B P_{\mathrm{ND}}$ changes may also reflect receptor internalization or altered conformation rather than occupancy by endogenous neurotransmitter. Our outcome measure $\left(B P_{N D}\right)$ cannot specify directly which interpretation is most appropriate. Moreover, because we scanned only males, we do not know whether our results translate directly to females. However, our behavioral control data showing elevated pain threshold when watching comedy versus drama clips together with friends suggest that laughter likely triggers similar opioid release in female subjects. To maximize statistical power, our study used a highly natural laughter manipulation coupled with a low-level baseline condition (i.e., spending $30 \mathrm{~min}$ alone before the scan); 
therefore, it can be questioned whether our results would be specific to social laughter versus the mere social presence of others. However, our behavioral control data suggest that only social laughter rather than mere social presence of other individuals (or pleasure, see Dunbar et al., 2012) leads to endogenous opioid release. Finally, due to limited sample size, this first in vivo demonstration of laughter-induced opioid release should be considered as preliminary and interpreted with some caution.

\section{Conclusions}

We conclude that baseline level and modulation of the $\mu$-opioid system by social laughter could be an important neurochemical mechanism reinforcing and maintaining social bonds between humans. These data agree with animal studies (Keverne et al., 1989) in suggesting that the calming effects of endogenous opioidergic activity during social interactions constitute a key mechanism promoting intragroup affiliation and bonding. Social touching and grooming are important means for bonding in humans and other primates (Dunbar and Shultz, 2010; Suvilehto et al., 2015); however, the present findings underline the central role of nonverbal communication and laughter in modulating interpersonal bonds and making large social networks possible.

\section{References}

Alenius S, Ruotsalainen U (1997) Bayesian image reconstruction for emission tomography based on median root prior. Eur J Nucl Med 24:258-265. CrossRef

Barr CS, Schwandt ML, Lindell SG, Higley JD, Maestripieri D, Goldman D, Suomi SJ, Heilig M (2008) Variation at the mu-opioid receptor gene (OPRM1) influences attachment behavior in infant primates. Proc Natl Acad Sci U S A 105:5277-5281. CrossRef Medline

Berk LS, Tan SA, Fry WF, Napier BJ, Lee JW, Hubbard RW, Lewis JE, Eby WC (1989) Neuroendocrine and stress hormone changes during mirthful laughter. Am J Med Sci 298:390-396. CrossRef Medline

Broadhead WE, Kaplan BH, James SA, Wagner EH, Schoenbach VJ, Grimson R, Heyden S, Tibblin G, Gehlbach SH (1983) The epidemiologic evidence for a relationship between social support and health. Am J Epidemiol 117:521-537. CrossRef Medline

Colasanti A, Rabiner EA, Lingford-Hughes A, Nutt DJ (2011) Opioids and anxiety. J Psychopharmacol 25:1415-1433. CrossRef Medline

Critchley HD, Wiens S, Rotshtein P, Ohman A, Dolan RJ (2004) Neural systems supporting interoceptive awareness. Nat Neurosci 7:189-195. CrossRef Medline

Curry OS, Dunbar RIM (2013) Sharing a joke: the effects of a similar sense of humor on affiliation and altruism. Evolution and Human Behavior 34:125-129. CrossRef

Darwin C (1872) Expression of the emotions in man and animals. London: John Murray.

Davila Ross M, Owren MJ, Zimmermann E (2009) Reconstructing the evolution of laughter in great apes and humans. Curr Biol 19:1106-1111. CrossRef Medline

Dunbar RI (1991) Functional significance of social grooming in primates. Folia Primatologica 57:121-131. CrossRef

Dunbar RI (2008) Mind the gap: or why humans aren't just great apes. Proceedings of the British Academy 154:403-423.

Dunbar RI (2012) Bridging the bonding gap: the transition from primates to humans. Philos Trans R Soc Lond B Biol Sci 367:1837-1846. CrossRef Medline

Dunbar RI, Shultz S (2010) Bondedness and sociality. Behaviour 147:775803.

Dunbar RI, Baron R, Frangou A, Pearce E, van Leeuwen EJ, Stow J, Partridge G, MacDonald I, Barra V, van Vugt M (2012) Social laughter is correlated with an elevated pain threshold. Proc Biol Sci 279:1161-1167. CrossRef Medline

Eickhoff SB, Stephan KE, Mohlberg H, Grefkes C, Fink GR, Amunts K, Zilles K (2005) A new SPM toolbox for combining probabilistic cytoarchitectonic maps and functional imaging data. Neuroimage 25:1325-1335. CrossRef Medline

Fabre-Nys C, Meller RE, Keverne EB (1982) Opiate antagonists stimulate affiliative behaviour in monkeys. Pharmacol Biochem Behav 16:653-659. CrossRef Medline

Gabilondo AM, Meana JJ, García-Sevilla JA (1995) Increased density of muopioid receptors in the postmortem brain of suicide victims. Brain Res 682:245-250. CrossRef Medline

Graves FC, Wallen K, Maestripieri D (2002) Opioids and attachment in rhesus macaque (Macaca mulatta) abusive mothers. Behav Neurosci 116: 489-493. CrossRef Medline

Gunn RN, Lammertsma AA, Hume SP, Cunningham VJ (1997) Parametric imaging of ligand-receptor binding in PET using a simplified reference region model. Neuroimage 6:279-287. CrossRef Medline

Henriksen G, Willoch F (2008) Imaging of opioid receptors in the central nervous system. Brain 131:1171-1196. CrossRef Medline

Hiller JM, Fan LQ (1996) Laminar distribution of the multiple opioid receptors in the human cerebral cortex. Neurochem Res 21:1333-1345. CrossRef Medline

Hirvonen J, Aalto S, Hagelberg N, Maksimow A, Ingman K, Oikonen V, Virkkala J, Någren K, Scheinin H (2009) Measurement of central muopioid receptor binding in vivo with PET and [11C]carfentanil: a testretest study in healthy subjects. Eur J Nucl Med Mol Imaging 36:275-286. CrossRef Medline

Holt-Lunstad J, Smith TB, Baker M, Harris T, Stephenson D (2015) Loneliness and social isolation as risk factors for mortality: a meta-analytic review. Perspect Psychol Sci 10:227-237. CrossRef Medline

Hsu DT, Sanford BJ, Meyers KK, Love TM, Hazlett KE, Wang H, Ni L, Walker SJ, Mickey BJ, Korycinski ST, Koeppe RA, Crocker JK, Langenecker SA, Zubieta JK (2013) Response of the $\mu$-opioid system to social rejection and acceptance. Mol Psychiatry 18:1211-1217. CrossRef Medline

Karlsson HK, Tuominen L, Tuulari JJ, Hirvonen J, Parkkola R, Helin S, Salminen P, Nuutila P, Nummenmaa L (2015) Obesity is associated with decreased mu-opioid but unaltered dopamine D-2 receptor availability in the brain. J Neurosci 35:3959-3965. CrossRef Medline

Kätsyri J, Hari R, Ravaja N, Nummenmaa L (2013) The opponent matters: elevated fMRI reward responses to winning against a human versus a computer opponent during interactive video game playing. Cereb Cortex 23:2829-2839. CrossRef Medline

Kennedy SE, Koeppe RA, Young EA, Zubieta JK (2006) Dysregulation of endogenous opioid emotion regulation circuitry in major depression in women. Arch Gen Psychiatry 63:1199-1208. CrossRef Medline

Keverne EB, Martensz ND, Tuite B (1989) Beta-endorphin concentrations in cerebrospinal-fluid of monkeys are influenced by grooming relationships. Psychoneuroendocrinology 14:155-161. CrossRef Medline

Liu L, Newschaffer CJ (2011) Impact of social connections on risk of heart disease, cancer, and all-cause mortality among elderly Americans: Findings from the Second Longitudinal Study of Aging (LSOA II). Arch Gerontol Geriatr 53:168-173. CrossRef Medline

Meller RE, Keverne EB, Herbert J (1980) Behavioral and endocrine effects of naltrexone in male talapoin monkeys. Pharmacol Biochem Behav 13:663672. CrossRef Medline

Mireault GC, Crockenberg SC, Sparrow JE, Cousineau K, Pettinato C, Woodard K (2015) Laughing matters: Infant humor in the context of parental affect. J Exp Child Psychol 136:30-41. CrossRef Medline

Moles A, Kieffer BL, D'Amato FR (2004) Deficit in attachment behavior in mice lacking the mu-opioid receptor gene. Science 304:1983-1986. CrossRef Medline

Nummenmaa L, Tuominen LJ (2017) Opioid system and human emotions. Br J Pharmacol. In press.

Nummenmaa L, Manninen S, Tuominen L, Hirvonen J, Kalliokoski KK, Nuutila P, Jääskeläinen IP, Hari R, Dunbar RI, Sams M (2015) Adult attachment style Is associated with cerebral $\mu$-opioid receptor availability in humans. Hum Brain Mapp 36:3621-3628. CrossRef Medline

Olausson H, Lamarre Y, Backlund H, Morin C, Wallin BG, Starck G, Ekholm S, Strigo I, Worsley K, Vallbo AB, Bushnell MC (2002) Unmyelinated tactile afferents signal touch and project to insular cortex. Nat Neurosci 5:900-904. CrossRef Medline

Panksepp J, Herman BH, Vilberg T, Bishop P, DeEskinazi FG (1980) Endogenous opioids and social behaviour. Neurosci Biobehav Rev 4:473487. CrossRef Medline

Peciña M, Zubieta JK (2015) Molecular mechanisms of placebo responses in humans. Mol Psychiatry 20:416-423. CrossRef Medline

Preuschoft S (1992) "Laughter" and "smile" in Barbary macaques (Macaca sylvanus). Ethology 91:220-236. 
Provine RR (2004) Laughing, tickling, and the evolution of speech and self. Curr Dir Psychol Sci 13:215-218. CrossRef

Rütgen M, Seidel EM, Riečanský I, Lamm C (2015a) Reduction of empathy for pain by placebo analgesia suggests functional equivalence of empathy and first-hand emotion experience. J Neurosci 35:8938-8947. CrossRef Medline

Rütgen M, Seidel EM, Silani G, Riečanský I, Hummer A, Windischberger C, Petrovic P, Lamm C (2015b) Placebo analgesia and its opioidergic regulation suggest that empathy for pain is grounded in self pain. Proc Natl Acad Sci U S A 112:E5638-E5646. CrossRef Medline

Sander CY, Hooker JM, Wey HY, Wilson CM, Catana C, Rosen B, Mandeville JB (2014) Effects of simultaneously measured flow changes on D2/D3 radiotracer dynamics. In: 10th International symposium on functional neuroreceptor mapping of the living brain. Amsterdam.

Sander K, Scheich H (2005) Left auditory cortex and amygdala, but right insula dominance for human laughing and crying. J Cogn Neurosci 17: 1519-1531. CrossRef Medline

Sauter DA, Eisner F, Ekman P, Scott SK (2010) Cross-cultural recognition of basic emotions through nonverbal emotional vocalizations. Proc Natl Acad Sci U S A 107:2408-2412. CrossRef Medline

Scott SK, Lavan N, Chen S, McGettigan C (2014) The social life of laughter. Trends Cogn Sci 18:618-620. CrossRef Medline

Silk JB, Alberts SC, Altmann J (2003) Social bonds of female baboons enhance infant survival. Science 302:1231-1234. CrossRef Medline

Singer T, Seymour B, O’Doherty J, Kaube H, Dolan RJ, Frith CD (2004)
Empathy for pain involves the affective but not sensory components of pain. Science 303:1157-1162. CrossRef Medline

Suvilehto JT, Glerean E, Dunbar RI, Hari R, Nummenmaa L (2015) Topography of social touching depends on emotional bonds between humans. Proc Natl Acad Sci U S A 112:13811-13816. CrossRef Medline

Tzourio-Mazoyer N, Landeau B, Papathanassiou D, Crivello F, Etard O, Delcroix N, Mazoyer B, Joliot M (2002) Automated anatomical labeling of activations in SPM using a macroscopic anatomical parcellation of the MNI MRI single-subject brain. Neuroimage 15:273-289. CrossRef Medline

Waller B, Dunbar R (2005) Differential behavioural effects of silent bared teeth display and relaxed open mouth display in chimpanzees (Pan troglodytes). Ethology 111:129-142. CrossRef

Way BM, Taylor SE, Eisenberger NI (2009) Variation in the mu-opioid receptor gene (OPRM1) is associated with dispositional and neural sensitivity to social rejection. Proc Natl Acad Sci U S A 106:15079-15084. CrossRef Medline

Wicker B, Keysers C, Plailly J, Royet JP, Gallese V, Rizzolatti G (2003) Both of us disgusted in my insula: the common neural basis of seeing and feeling disgust. Neuron 40:655-664. CrossRef Medline

Wild B, Rodden FA, Grodd W, Ruch W (2003) Neural correlates of laughter and humour. Brain 126:2121-2138. CrossRef Medline

Young LJ, Lim MM, Gingrich B, Insel TR (2001) Cellular mechanisms of social attachment. Horm Behav 40:133-138. CrossRef Medline

Zubieta JK, Dannals RF, Frost JJ (1999) Gender and age influences on human brain mu-opioid receptor binding measured by PET. Am J Psychiatry 156:842-848. CrossRef Medline 